\title{
The oxytocin receptor gene predicts brain activity during an emotion recognition task in autism
}

\author{
Florina Uzefovsky ${ }^{1,2^{*}} \mathbb{D}$, Richard A. I. Bethlehem² ${ }^{2}$ Simone Shamay-Tsoory ${ }^{3}$, Amber Ruigrok ${ }^{2}$, Rosemary Holt ${ }^{2}$, \\ Michael Spencer ${ }^{2}$, Lindsay Chura ${ }^{2}$, Varun Warrier ${ }^{2}$, Bhismadev Chakrabarti ${ }^{4}$, Ed Bullmore ${ }^{2}$, John Suckling ${ }^{2}$, \\ Dorothea Floris 2,5 and Simon Baron-Cohen 2,6
}

\begin{abstract}
Background: Autism is a highly varied and heritable neurodevelopmental condition, and common variants explain approximately $50 \%$ of the genetic variance of autism. One of the genes implicated in autism is the oxytocin receptor (OXTR). The current study combined genetic and brain imaging (FMRI) data to examine the moderating effect of genotype on the association between diagnosis and brain activity in response to a test of cognitive empathy.

Methods: Participants were adolescents (mean age $=14.7 \pm 1.7$ ) who were genotyped for single nucleotide polymorphisms (SNPs) within the OXTR and underwent functional brain imaging while completing the adolescent version of the 'Reading the Mind in the Eyes' Test (Eyes Test).

Results: Two (rs2254298, rs53576) of the five OXTR SNPs examined were significantly associated with brain activity during the Eyes Test, and three of the SNPs (rs2254298, rs53576, rs2268491) interacted with diagnostic status to predict brain activity. All of the effects localized to the right supramarginal gyrus (rSMG) and an overlap analysis revealed a large overlap of the effects. An exploratory analysis showed that activity within an anatomically defined rSMG and genotype can predict diagnostic status with reasonable accuracy.

Conclusions: This is one of the first studies to investigate OXTR and brain function in autism. The findings suggest a neurogenetic mechanism by which OXTR-dependent activity within the ISMG is related to the aetiology of autism.
\end{abstract}

Keywords: Autism, Oxytocin receptor, fMRl, Supramarginal gyrus, Imaging genetics

\section{Background}

Autism is a highly varied neurodevelopmental condition characterised by deficits in social interaction and communication, alongside unusually repetitive behaviour and extremely narrow interests. Other characteristics of autism include a resistance to unexpected change and atypical sensory sensitivity (DSM-5, 2013).

One of the main characteristics of autism is difficulties in social cognition, and in particular cognitive empathy

\footnotetext{
* Correspondence: florina@bgu.ac.il

'Department of Psychology and Zlotowski Center for Neuroscience, Ben Gurion University of the Negev, 84105 Be'er Sheva, Israel

${ }^{2}$ Autism Research Centre, Department of Psychiatry, University of Cambridge, Cambridge, UK

Full list of author information is available at the end of the article
}

[1]. Cognitive empathy is defined as the ability to identify the mental state of the other [2]. One of the most well-validated and widely used measures of cognitive empathy is the 'Reading the Mind in the Eyes' Test (Eyes Test) [3]. Individuals diagnosed with autism tend to score lower on this measure than controls [3, 4], and other measures of social cognition show the same pattern $[1,3,5]$. A recent study found that certain subgroups within autism score lower than others [6] and a whole genome association study of performance on the Eyes Test suggests modest but significant heritability [7].

Autism manifests considerable heterogeneity, varying in clinical presentation across a spectrum of behaviours, as well as in levels of intellectual impairment and degree 
of delay in language development $[6,8]$. In line with this, the genetic aetiology of autism is heterogeneous and hundreds of genes are hypothesised to be implicated [9], with about $50 \%$ of the genetic effect attributed to common genetic variations [10]. This phenotypic and genetic heterogeneity is also evident in studies of the brain [11]. Studies of the anatomical and functional brain differences in autism versus typically developing individuals yield mixed results $[12,13]$. One way of gaining additional insight into the biological basis of autism is by combining data regarding genetic variation and brain imaging in a single analysis $[14,15]$. This is the aim of the current investigation.

\section{Oxytocin}

Here, we focused specifically on the oxytocin receptor $(O X T R)$ gene, as it has been previously linked with social cognition and behaviour in the typical population, as well as with autism [16]. Oxytocin (OXT) is a nonapeptide with a long evolutionary history and a well-established role in animal and human social behaviour and cognition [17]. OXT has a major role in the 'social brain', i.e. in brain regions that have been clearly associated with social cognition $[18,19]$. The 'social brain' includes areas such as the amygdala, insula, medial prefrontal cortex, superior temporal sulcus, anterior cingulate cortex, temporoparietal junction, and inferior parietal lobule $[20,21]$. The effects of OXT on the social brain are likely mediated by its receptor-the OXTR. Indeed, a recent study using in vivo arterial spin labelling to identify changes in cerebral blood flow following intranasal administration of OXT implicated many areas within the social brain [22], suggesting a broad expression pattern of the OXTR. An analysis of OXTR expression patterns using RNAseq revealed that it is broadly expressed in subcortical and cortical regions [23].

\section{Association of OXTR with both social cognition and autism} Single nucleotide polymorphisms (SNPs) in the OXTR have been associated with autism in different populations [24-30], especially related to the social domain in autism [31, 32], although null-findings are also reported [33-35]. Epigenetic markers on the OXTR have also been associated with autism [36, 37], and oxytocin (OXT) administration has been shown to improve social symptoms in autism [38-45] (but see also [46]). Similar findings of association between OXTR and social cognition have been reported for typical populations, including an association with performance on the Eyes Test $[47,48]$ and empathy $[49,50]$, as well as with prosocial behaviour [51, 52], partner bonding [53], parent-child relationship [54], and others.

The involvement of the OXT system in social cognition is further supported by studies in which participants are given intranasal doses of OXT. In these studies, OXT administration is shown to increase cognitive empathy, including as measured by the Eyes Test [43, 55, 56]. Taken together, these findings suggest two conclusions. First, OXT is associated with social cognition and social behaviour across the entire spectrum of social ability-both in typical population and in autism. Second, OXT and OXTR are also associated with individual differences in social cognition and behaviour [57]. For example, OXT administration had a stronger effect in improving empathic accuracy for those scoring higher on the autism spectrum quotient (AQ; [58]), i.e. typical males with higher levels of autistic traits [59]. Similarly, those who had the most impaired eye-contact also improved the most after receiving a dose of OXT [44].

\section{Oxytocin in the brain}

Most studies of the role of OXT in the brain are conducted in typical populations and utilise intranasal administration of OXT. These studies typically find that OXT induces decreased activation in the amygdala during emotion processing, although this effect may differ in men and women $[18,60,61]$. Few studies have examined the effects of OXT in autism, and these usually show that OXT administration is associated with the recovery of a typical pattern of activation in certain brain areas $[40,62]$. Moreover, a recent study extended these findings by showing that the effect of OXT administration on brain function (increased activity and connectivity between dorsal anterior cingulate cortex (ACC) and dorsomedial prefrontal cortex ( $\mathrm{dmPFC})$ ) is dependent on OXTR genotype [63].

One other previous study combined imaging and genetics to study OXTR in autism, and that study focused on the reward circuitry and especially the nucleus accumbens (NAcc) [64]. Their findings show an OXTR-dependent change in the connectivity of the reward circuitry in children with autism during resting state. Apart from this study, all other imaging genetics studies of OXTR conducted in typical Caucasian or non-Caucasian populations [50,65-73] implicate the structure and function of the amygdala and the hypothalamus as most associated with OXTR genotype, but also find associations with other parts of the social brain, such as the striatum and dmPFC. Moreover, a recent study reported a sex-specific association between the OXTR SNP rs2254298 and connectivity in the default mode network (DMN) [72]. Due to the broad distribution of the OXTR and evidence for its potential to affect many brain areas [22, 23, 60,72], we chose an unconstrained whole-brain analysis approach. The aim of the current study was to better understand the complex interaction between oxytocin genotype, brain function, and autism, by integrating OXTR genotype and brain 
imaging data in a sample of adolescents (aged 12.0118.53 years) with and without an autism diagnosis. Here, we focused on social cognition, and specifically the ability to recognise emotions, which is a hallmark difficulty in autism [3]. This is one of the first studies, to our knowledge, to take an imaging genetics approach to better understand the oxytocin-related aetiology of social cognition deficits in autism.

\section{Methods}

\section{Participants}

The participants of the current study are a subsample of those that participated in a previous study [74] who had provided DNA samples and had valid genotyping results. These were 38 adolescents aged 12-18 years (mean age $14.38 \pm 1.69$, 10 females) who were diagnosed with high-functioning autism or Asperger syndrome (henceforth, the autism group) and 33 (mean age $15.01 \pm 1.69$, 17 females) were neurotypically developing (henceforth, controls). Participants in the autism group had no other comorbidities, and diagnosis was confirmed using the Autism Diagnostic Observational Schedule-Generic (ADOS-G; [75]) and the Autism Diagnostic InterviewRevised (ADI-R; [76]). Participants with current or past medication use were not included in the current study. Details of the participants used in the current study appear in Table 1.

\section{Behavioral measures}

Participants' intelligence quotient (IQ) was assessed using the Wechsler Abbreviated Scale of Intelligence (WASI; [77]). In addition, parents reported on their child's autistic traits, using the adolescent version of the autism spectrum quotient (AQ; [78]). See details in Table 1.

\section{DNA extraction and genotyping}

Samples were collected using buccal swabs. DNA was extracted using the protocol described previously [79], at the Institute of Psychiatry, SGDP research centre, UK. Samples were genotyped by LGC Genomics Ltd. at Hoddesdon, UK, using PCR-based KASP technology.
Genotyping was conducted for seven oxytocin receptor (OXTR) single nucleotide olymorphisms (SNPs) rs7632287, rs2268491, rs237887, rs2254298, rs53576, rs2268493, and rs2228485. These SNPs were selected based on previous studies of associations with autism risk or individual variability in empathy and emotion recognition (see Table 2). Two of the SNPs had extremely low variability in the current sample (rs237887-only two no-risk carriers in the control group, and rs2268493-only two no-risk carriers in control and autism groups each). These SNPs were not analysed further. Analysis of linkage disequilibrium was conducted using LDlink [80] and the 1000 Genomes project database of European samples (see Fig. 1). Some of the SNP pairs had high $D^{\prime}$ values but low $R^{2}$ values, and therefore were still analysed separately. The pair rs2268491-rs2254298 was in high LD on both measures, and we refer to this in the "Discussion" section. For all SNPs, the high-risk allele carriers were compared to those homozygous for the low-risk allele. The distribution of genotype did not differ significantly between the diagnostic groups $\left(\chi^{2}>.056\right.$ for all SNP $\times$ group analyses).

\section{fMRI task}

Participants completed the adolescent version of the 'Reading the Mind in the Eyes' test (Eyes Test) as previously described [74]. The adolescent version of the Eyes Test is a simplified and fMRI suitable version of the adult test [3]. In this test, participants are presented with 32 pictures of the eye area and are asked to choose one of two words that best describes the mental state of the person depicted in each picture. A sex-judgment task using the same 32 pictures as stimuli was used as a control condition. The resulting contrast essentially allows to compare the difference between automatic processes of emotion recognition and explicit processing of emotional cues. In both cases, choice was indicted by pressing one of the two buttons on a button box held in their right hand. The tasks were organised in blocks of $23 \mathrm{~s}$ that included the presentation of four pictures for $5 \mathrm{~s}$ each, an inter-stimulus interval of $0.75 \mathrm{~s}$, and an

Table 1 Sample demographics

\begin{tabular}{|c|c|c|c|c|c|}
\hline & \multicolumn{2}{|l|}{ Autism group } & \multicolumn{2}{|l|}{ Control group } & \multirow[t]{2}{*}{ Significance testing } \\
\hline & Mean ( \pm SD) & Range & Mean ( \pm SD) & Range & \\
\hline$\overline{\text { Age }}$ & $14.38(1.69)$ & $12.01-18.53$ & $15.01(1.69)$ & $12.08-17.62$ & $t_{(69)}=-1.57, p=.121$ \\
\hline Full-scale IQ & $106.11(16.73)$ & $76-146$ & $112.18(11.62)$ & $83-136$ & $t_{(69)}=-1.75, p=.084$ \\
\hline Verbal IQ & $106.16(19.48)$ & $70-150$ & $111.27(12.22)$ & $87-142$ & $\mathrm{t}_{(69)}=-1.30, p=.197$ \\
\hline Performance IQ & $104.92(15.95)$ & $70-141$ & $110.58(10.94)$ & $83-132$ & $t_{(69)}=-1.72, p=.091$ \\
\hline $\mathrm{AQ}$ & $39(6.47)$ & $19-49$ & $9.58(5.99)$ & $1-24$ & $t_{(69)}=19.78, p<.001$ \\
\hline ADOS total & $11.50(4.18)$ & $7-26$ & & & \\
\hline
\end{tabular}

IQ intelligence quotient, $A Q$ autism spectrum quotient, SRS Social Responsiveness Scale 
Table 2 Studies that implicate OXTR SNPs in autism and social cognition

\begin{tabular}{|c|c|c|c|}
\hline SNP & Major/minor frequency allele & Associated with & References \\
\hline \multirow[t]{2}{*}{ rs2254298 } & $\mathrm{G} / \mathrm{A}$ & Autism and autistic traits & {$[28-30,32,87,88]$} \\
\hline & & Social cognition & {$[35,89-93]$} \\
\hline \multirow[t]{2}{*}{ rs53576 } & $\mathrm{G} / \mathrm{A}$ & Autism & {$[29,31,88,94,95]$} \\
\hline & & Social cognition & {$[35,50,52,55,75,92,96][101]$} \\
\hline \multirow[t]{2}{*}{ rs2268491 } & $\mathrm{C} / \mathrm{T}$ & Autism & {$[28]$} \\
\hline & & Social cognition & [89], [102] \\
\hline \multirow[t]{3}{*}{ rs7632287 } & $\mathrm{G} / \mathrm{A}$ & Autism & {$[28,34]$} \\
\hline & & Social traits in autism & {$[103]$} \\
\hline & & Social cognition & {$[89]$} \\
\hline \multirow[t]{2}{*}{ rs237887 } & $A / G$ & Autism & [28] \\
\hline & & Social cognition & [89], [102] \\
\hline rs2268493 & $\mathrm{T} / \mathrm{C}$ & Autism & {$[27]$} \\
\hline rs2228485 & $T / C$ & Social cognition & [104] \\
\hline
\end{tabular}

interblock interval of $2 \mathrm{~s}$. A total of 16 blocks were presented (8 mental state and 8 sex judgment), resulting in an overall presentation time of $7 \mathrm{~min}$. The order of the blocks was counterbalanced across participants in each group. The stimuli were presented using e-Prime version 2.0 professional (Psychological Software Tools, USA).

\section{fMRI collection and preprocessing}

Participants were scanned using a Siemens 3-T Tim Trio scanner (Siemens Healthcare, Germany) at the Medical
Research Council Cognition and Brain Sciences Unit (MRC CBU) in Cambridge, UK. Echoplanar imaging (EPI) was collected with the following parameters: repetition time $(\mathrm{TR})=2000 \mathrm{~ms}$, echo time $(\mathrm{TE})=30 \mathrm{~ms}$, voxel size $3 \times 3 \times 3 \mathrm{~mm}, 32$ slices acquired sequentially descending in the transverse plane with a slice thickness of $3 \mathrm{~mm}$ and an interslice gap of $0.75 \mathrm{~mm}$, and flip angle $=60^{\circ}$. A structural image (magnetization prepared rapid gradient echo: MPRAGE) was also acquired for co-registration and normalisation purposes, with the

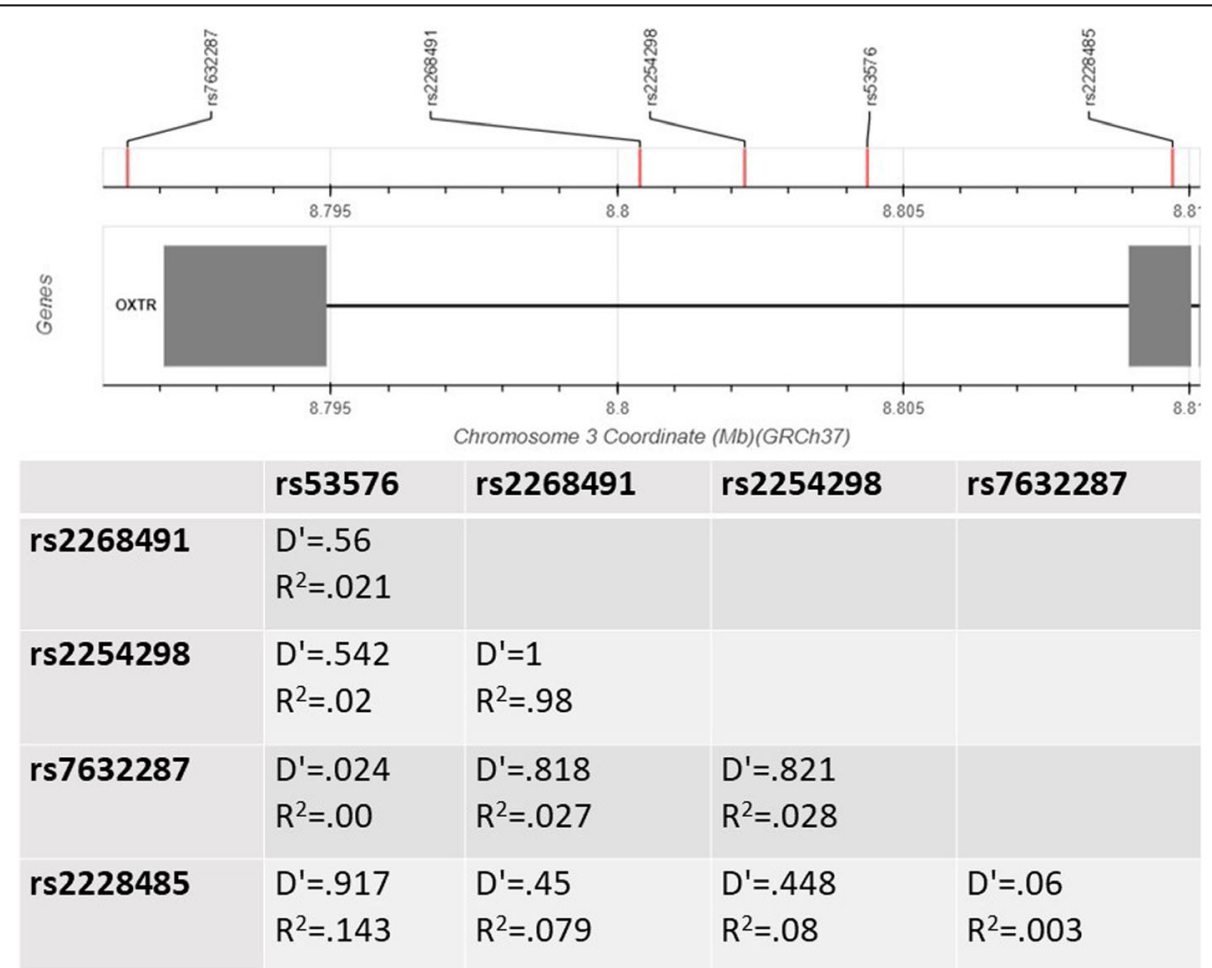

Fig. 1 Linkage disequilibrium analysis. The SNP which were included in the analyses were examined for linkage disequilibrium (LD). The figure containing SNP's locations was automatically created by LDlink [80] 
following parameters: voxel size $1 \times 1 \times 1 \mathrm{~mm}, \mathrm{TR}=$ $2250 \mathrm{~ms}, \mathrm{TE}=2.98 \mathrm{~ms}$, inversion time $(\mathrm{TI})=900 \mathrm{~ms}$, flip angle $=9^{\circ}$, and total scan time $4 \mathrm{~min} 32 \mathrm{~s}$.

Preprocessing was done using the SPM12 package (Wellcome Trust Centre for Neuroimaging, UK, http:// www.fil.ion.ucl.ac.uk/spm). Each volume was first slice-time corrected using the middle slice as a reference. Slice-time corrected volumes were spatially aligned to the first volume. In order to maximise the best possible individual normalisation, we chose a unified segmentation approach [81] to indirectly normalise images to MNI space. Individual T1-weighted images were first co-registered to the realigned fMRI volumes. Segmentation was done based on a template created using the Template-O-Matic toolbox [82] in SPM8. This toolbox generates tissue maps that are based on a healthy pediatric sample and are made study-specific based on the age and sex composition of the sample used. Parameters from the T1 normalisation were then applied to the functional volumes, and these were subsequently resliced to 2-mm isotropic voxels. We chose this resolution in order to maintain compatibility with a previous publication which used a bigger version of the same dataset [74]. However, we have used a relatively stringent criterion for significance testing, with all family-wise error (FWE) at $p<.001$. Finally, an $8-\mathrm{mm}$ full-width-half-maximum (FWHM) smoothing kernel was applied. An analysis of residual head motion during scanning using DVARS (i.e., the spatial root mean square of the data after temporal differencing) revealed no group differences (Additional file 1: Figure S1).

\section{Imaging analysis}

For each participant, a first-level analysis was preformed comparing hemodynamic response during mental state vs. sex judgment (F-contrast), thus controlling for other aspects of the task. Next, a second-level, full-factorial analysis using a whole-brain approach was conducted with diagnosis and genotype $(2 \times 2)$ as fixed factors and sex and age as nuisance covariates. The analysis was conducted for each SNP separately. Statistical outcomes were corrected for multiple comparisons using a family-wise error (FWE) correction based on the cluster size. We also report the identified cluster size for each analysis. The SPM Anatomy toolbox was used to identify the significant clusters [83]. The MarsBaR toolbox [84] was used to extract the coefficients for each participant at each of the clusters identified in the previous analyses (clusters defined by main and interaction effects for rs2254298 and rs53576 and a cluster defined by an interaction effect for rs2268491). We then examined the correlation between the average activation levels and AQ scores within the autism and control groups separately. Overlap analysis was conducted using the fslmaths function in FSL [85]. Visualisation and labelling were done using MRIcron [86] and the Automated Anatomical Labelling Atlas [87].

\section{Exploratory analysis of anatomical region of interest}

Based on the findings described below, an exploratory of the activation within an anatomically defined rSMG was conducted. An anatomical mask was created using the Anatomy toolbox [83] in SPM12 (Wellcome Trust Centre for Neuroimaging, UK, http://www.fil.ion.ucl.ac.uk/spm, based on the following cytoarchitectonic areas PF, PFcm, PFm, PFop, and PFt). For each participant, a first-level analysis was preformed comparing hemodynamic response during mental state vs. sex judgment (t-contrast), and a second-level analysis with solely sex and age as nuisance covariates, thus creating a map of activation with no factorial constraints. Afterwards, MarsBaR [84] was used to extract the mean activation level for each participant within the anatomically defined rSMG. These values were used within a logistic regression along with genotype and the interaction between them to predict diagnostic status (autism/control). The analysis was conducted in SPSS v22, IBM, Inc.

\section{Results}

Participants in the autism group were significantly less accurate in their mental state judgements on the Eyes Test than the control group $(M=24.03, S D=6.99$ and $\mathrm{M}=27.76, \mathrm{SD}=2.29$ respectively, $t_{(61)}=-2.90$, Cohen's $d=0.72, p=.005)$. However, once genotype was considered as well (and sex and age were controlled for, as in the imaging analyses below), this effect disappeared (all $p$ values $>.083$ ).

\section{Genotype distributions}

Autism and control groups did not differ on genotype distribution for any of the examined SNPs, AQ ratings, or RMET scores. The exception was for rs7632287, for which the major frequency (low risk) genotype appeared more frequently than expected in the autism group, and scored higher on the AQ, as compared to the low-frequency (high risk) genotype (see Table 3 ).

\section{Imaging genetic analysis}

For each of the five SNPs that were analysed, a main effect of diagnosis, genotype, and the interaction between the two factors was examined $(2 \times 2)$. In none of the analyses was diagnosis a significant predictor of activation. We report the nominal $p$ value for these analyses and interpret the results based on a more stringent Bonferroni-corrected significance criterion of $p=.01$, in order to control for the testing of the five SNPs. 
Table 3 Distributions by genotype

\begin{tabular}{llllll}
\hline & Genotype & Autism & Control & AQ & RMET \\
\hline rs53576 & GG & 15 & 6 & 31 & 80.76 \\
& A & 23 & 26 & 23.67 & 81.1 \\
& & $X^{2}=0.059$ & & $F=3.11$ & $F=.005$ \\
rs2268491 & CC & 27 & 28 & 23.84 & 80.72 \\
& T & 12 & 5 & 31.12 & 82.62 \\
& & $X^{2}=0.12$ & & $F=2.73$ & $F=.15$ \\
rs2254298 & GG & 27 & 27 & 24.09 & 80.43 \\
& A & 11 & 5 & 31.13 & 85.42 \\
& & $X^{2}=0.186$ & & $F=2.38$ & $F=1.07$ \\
rs7632287 & GG & 28 & 15 & 29.72 & 82.86 \\
& A & 11 & 18 & 19.38 & 79.13 \\
& & $X^{2}=5.156^{*}$ & & $F=7.89^{*}$ & $F=.758$ \\
rs2228485 & T & 22 & 16 & 27.08 & 81.74 \\
& C & 17 & 16 & 24.27 & 80.21 \\
& & $X^{2}=0.290$ & & $F=.535$ & $F=.725$ \\
\hline
\end{tabular}

$A Q$ autism spectrum quotient (adolescent version) [81] ${ }^{*} p<.05$

rs2254298 Genotype of rs2254298 was associated with significant hyperactivation in an area corresponding to the right supramarginal gyrus (rSMG) and the right inferior parietal lobule (rIPL) $(F(1,60)=11.97$, nominal $p$ value ${ }_{(\text {FWE-corr })}=0.010$, cluster size $\left.=163\right)$, as was the interaction between genotype and diagnosis (nominal $p$ value $($ FWE-corr $)=0.009$, cluster size $=164)$. Figure 2 presents the beta values extracted from the active cluster stratified by group and genotype. The effect is driven by hyperactivation in A-carriers in the control group. rs53576 Genotype of rs53576 was also associated with significant hyperactivation in an area corresponding to the rSMG and $\operatorname{rIPL}(F(1,60)=11.97$, nominal $p$ value $($ FWE-corr $)=0.006$, cluster size $=157)$. The interaction between genotype and diagnosis was only nominally significant (nominal $p$ value $($ FWE-corr) $=0.034$, cluster size $=$ 114). Figure 3 presents the beta values extracted from the active cluster stratified by group and genotype. The effect is driven by hyperactivation in GG-carriers in the control group.

rs2268491 For this SNP, only the interaction between genotype and diagnosis, but not the genotype, was associated with a differential activation in an area corresponding to the $\operatorname{rSMG}$ and $\operatorname{rIPL}(F(1,60)=11.93$, nominal $p$ value (FWE-corr) $=0.009$, cluster size $=160$ ). The effect was driven by hyperactivation in the control T-carriers. See Fig. 4.

The SNPs rs2228485 and rs7632287 or their interactions with diagnosis did not yield any cluster that survived the family-wise error correction.

Overlap analysis As all the effects localised to the rSMG and rIPL, we turned to investigate the degree of overlap between these effects. We included all nominally significant effects in the following analyses: (1) overlap of genotype and interaction effect for each SNP, (2) overlap of main effects across SNPs, and (3) overlap of the genotype by diagnosis effects across SNPs.

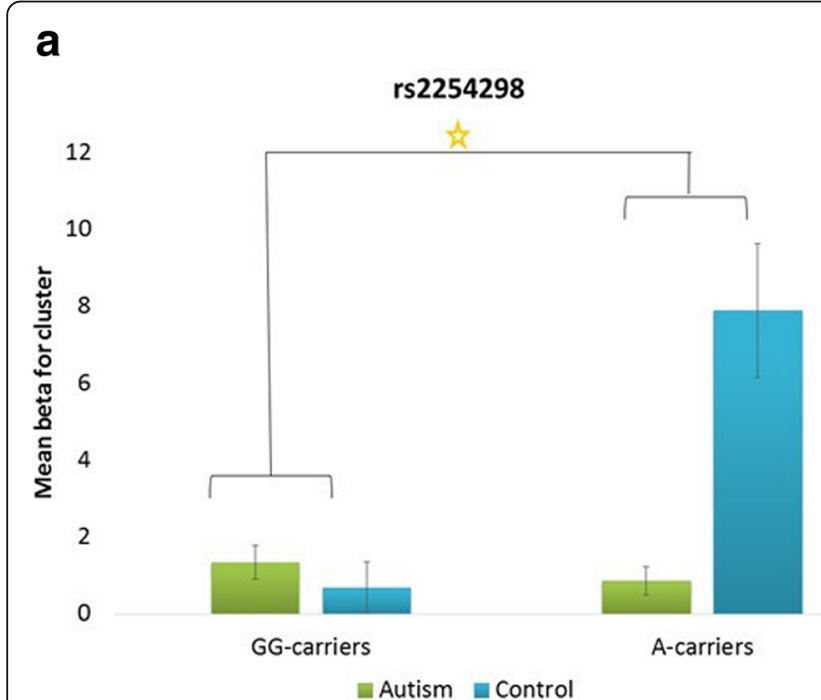

\section{b rs2254298 effect}

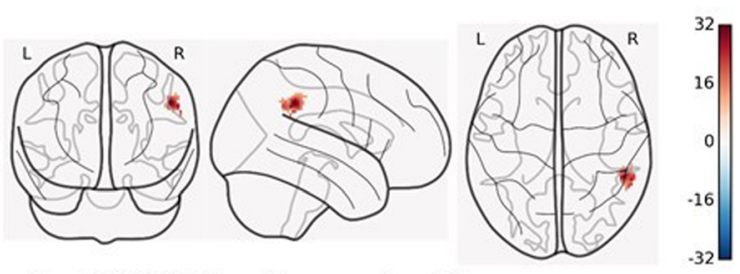

c) rs2254298 $\times$ diagnosis effect

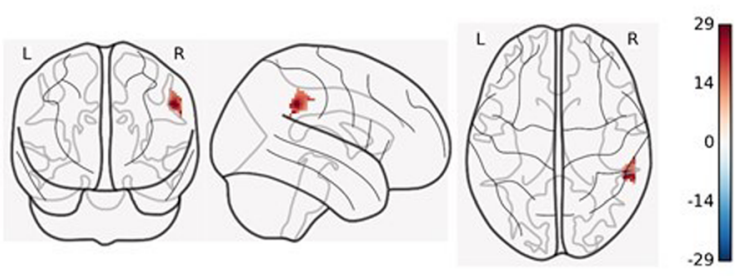

Fig. 2 Whole brain analysis of activity in response to a social decision task, depending on OXTR rs2254298 genotype and diagnostic status. Note: a Mean activation within the significant cluster stratified by OXTR rs2254298 genotype and diagnostic group. The mean values are based on the interaction analysis. Genotype was grouped based on the A-allele (GG vs GA and AA). The main effect of genotype and the interaction between genotype and diagnostic group were significant at corrected $p<.01$. b The corresponding activation map for the main effect of rs 2254298 genotype. c The corresponding activation map for the interaction effect between rs2254298 genotype and diagnostic status 


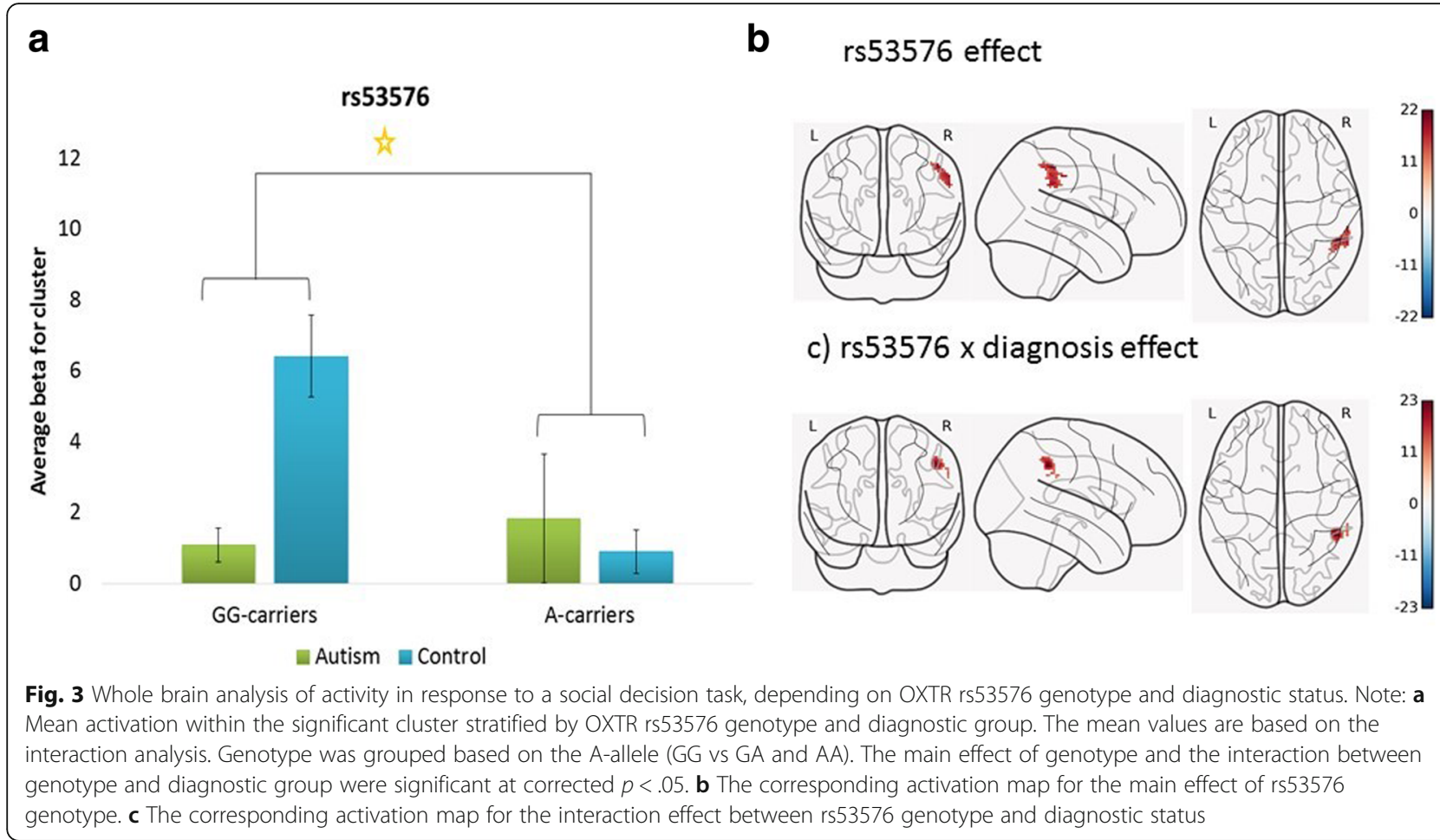

(1) For rs2254298, the area activated depending on the genotype and the area activated depending on the interaction between genotype and diagnosis overlapped by 89 voxels or $54.60 \%$ (size of main effect served as the basis), within the rSMG

(Fig. 5a). The same overlap for rs53576 was of
$31.21 \%$ or 40 voxels within the rSMG and rIPL (Fig. 5b). For rs2268491, only an interaction effect was significant; therefore, no overlap effect was calculated.

(2) The overlap between the main effects of rs2254298 and rs53576 was calculated as 51 voxels or $31.29 \%$

\section{a}

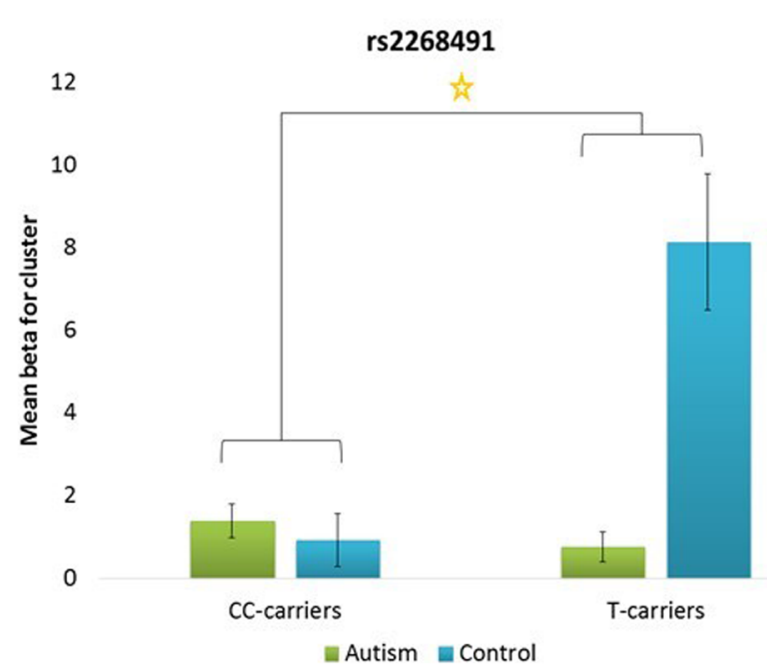

b rs2268491 $x$ diagnosis effect

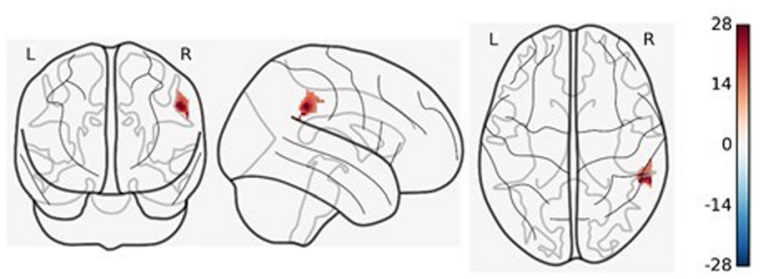

Fig. 4 Whole brain analysis of activity in response to a social decision task, depending on OXTR rs2268491 genotype and diagnostic status. Note: a Mean activation within the significant cluster stratified by OXTR rs2268491 genotype and diagnostic group. The mean values are based on the interaction analysis. Genotype was grouped based on the T-allele (CC vs CT and TT). The interaction between genotype and diagnostic group was significant at corrected $p<.01$. b The corresponding activation map for the interaction effect of rs2268491 genotype and diagnostic status 


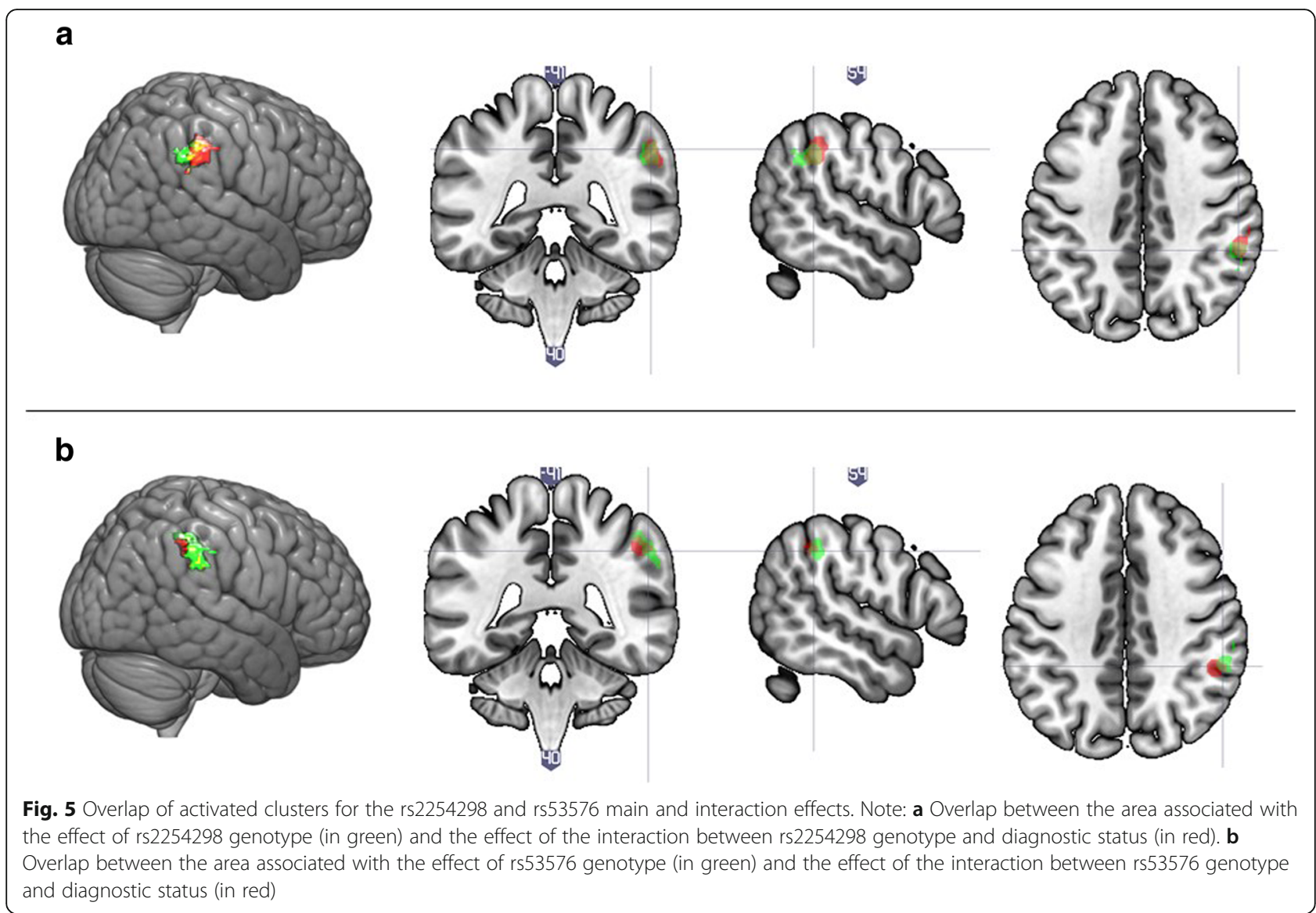

(size of the effect for rs2254298 served as the basis) within the rSMG (Fig. 6, top panel).

(3) The overlap between the interaction effects of rs 2254298 and rs 2268491 was 156 voxels or $95.12 \%$ (size of the effect for rs2254298 served as basis) within the rSMG. The overlap between this and the interaction effect of rs53576 was 26 voxels or 15.85\% (again, size of the effect for rs 2254298 served as basis) within the rSMG. That is, two of the interaction effects (rs2254298 and rs2268491) localised to largely the same area, whereas the interaction effect of rs53576 localized to a slightly different region of the rSMG (Fig. 6, bottom panel).

Association with autistic traits For each of the significant findings, MarsBaR [84] was used to extract mean activation values for each participant. The correlation between activation and the adolescent version of the autism spectrum quotient (AQ; [78] was examined. As can be seen in Table 4, hyperactivation associated with the interaction between rs53576 genotype and diagnosis was nominally associated with the AQ score in the autism group. However, this association was not significant based on the Bonferroni-corrected $p$ value of $p=.01$.
Predicting diagnosis Based on these findings, we undertook an exploratory analysis, to check whether genotype and activation within an anatomically defined rSMG can predict diagnostic status. We conducted a logistic regression for each SNP with diagnostic status (autism/control) as the dependent variable. For all three SNP's, the models achieved good accuracy in the correct classification of individual participants to diagnostic groups. With the major caveat that this is an exploratory analysis, this suggests that activation in the rSMG in response to mental state judgments and the interaction between activation and OXTR SNP's can predict diagnostic status. See Table 5 for details.

\section{Discussion}

The current investigation aimed to understand the links between oxytocin receptor genotype, brain activity in response to an explicit cognitive empathy task, and autism. As autism encompasses a spectrum of manifestations, we expected to find subgrouping within those diagnosed with autism. We found that diagnostic status interacts with OXTR genotype to predict activation within the right supramarginal gyrus and the right inferior parietal lobule during a mental state judgment task. Two (rs2268491 and rs2254298, with rs53576 showing the 


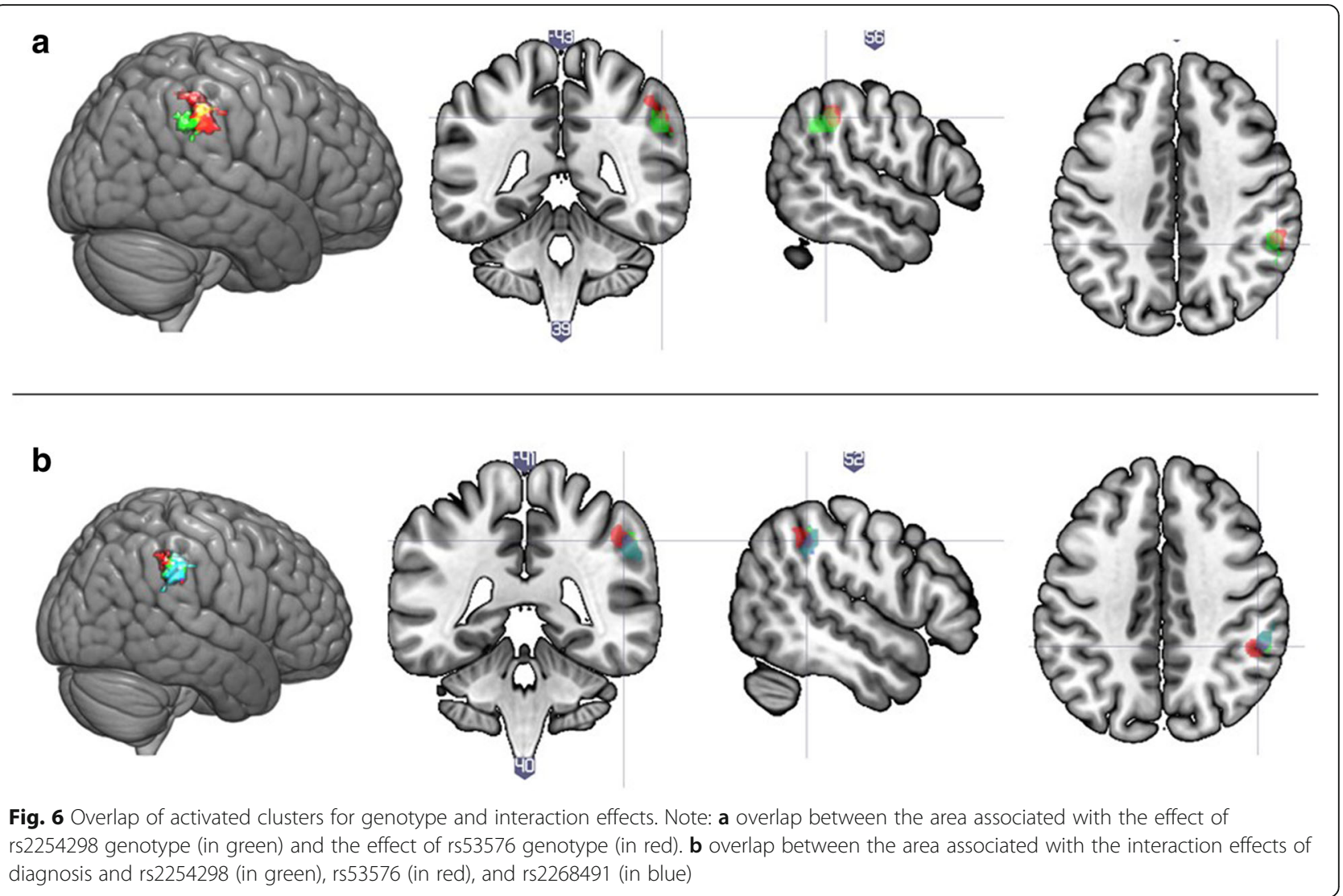

same effect nominally) out of the five SNPs examined showed a similar effect of differential activation based on diagnostic status, and two of the SNPs (rs2254298 and rs53576) were associated with activation, all within the rSMG and rIPL. Interestingly, the interaction showed a crossover effect, whereby an allele showing overactivation in the control group shows underactivation in the autism group and vice versa. The effects not only localised to the rSMG, but largely to the same cluster within the rSMG (with some distinct effect for the interaction between rs53576 and diagnosis, which was only nominally significant). The degree of the overlap in effect between rs2254298 and rs2268491 is expected as these two SNPs are in high LD $\left(R^{2}=.98, D^{\prime}=1\right)$. Other

Table 4 Association between brain activity in the right supramarginal gyrus and autism traits

\begin{tabular}{llll}
\hline \multicolumn{1}{l}{ Correlation with AQ } & Autism group & Control group \\
\hline rs53576 Genotype $\times$ diagnosis & $r=.342, p=.041^{*}$ & $r=-.179, p=.327$ \\
Genotype & $r=.221, p=.196$ & $r=-.136, p=.459$ \\
rs2254298 Genotype $\times$ diagnosis & $r=.067, p=.699$ & $r=-.151, p=.410$ \\
& Genotype & $r=.246, p=.149$ & $r=-.208, p=.254$ \\
rs2268491 Genotype $\times$ diagnosis & $r=.088, p=.603$ & $r=-.150, p=.404$ \\
\hline $\begin{array}{l}\text { AQ autism spectrum quotient (adolescent version) [81] } \\
\text { *Nominal significance }\end{array}$
\end{tabular}

SNP pairs show moderate LD (rs53576 with rs2268491; $R^{2}=.021, D^{\prime}=.56$ and with $\mathrm{rs} 2254298 ; R^{2}=.019, D^{\prime}$ $=.54$ ). As such, these consistent findings suggest an overall effect for the OXTR gene within this possibly functional locus, and in particular implicate the rSMG. Moreover, activation within an anatomically defined rSMG predicted diagnostic status in analysis of two of the three analysed OXTR SNPs (rs2254298, rs2268491), and the interaction between activation and genotype was significant for all three SNPs.

The effects of OXTR genotype localise to the rSMG, and this is in line with a study showing that OXTR methylation is associated with activity in the supramarginal gyrus and the dorsal anterior cingulate cortex (ACC) [37]. Interestingly, an fMRI study that investigated emotional egocentricity bias (EEB) found that overcoming such bias, i.e. being able to empathise with another even when the other's feelings differ from your own, is related to hyperactivity of the rSMG. Moreover, disrupting the activity of the rSMG using transcranial magnetic stimulation (TMS) resulted in increased bias [88]. In the above-mentioned study, EEB was manipulated using a touch paradigm in which participants rated the pleasantness of tactile stimulation for themselves and another participant while experiencing either congruent or incongruent stimulation. The difference between 
Table 5 Predicting diagnostic status

\begin{tabular}{|c|c|c|c|c|c|c|c|c|c|}
\hline & \multicolumn{3}{|c|}{ rs2268491 } & \multicolumn{3}{|c|}{ rs2254298 } & \multicolumn{3}{|l|}{ rs53576 } \\
\hline & $B$ & Sig & OR & $B$ & Sig & OR & $B$ & Sig & $\mathrm{OR}$ \\
\hline Sex & -1.066 & .073 & .345 & -1.185 & .053 & .306 & -1.401 & .020 & .246 \\
\hline Age & .161 & .332 & 1.174 & .179 & .290 & 1.196 & .201 & .226 & 1.223 \\
\hline rSMG activation & -1.419 & $.018^{*}$ & .242 & -1.599 & $.014^{*}$ & .202 & -1.051 & .068 & .350 \\
\hline Genotype & -.599 & .412 & .549 & -.347 & .645 & .707 & .704 & .285 & 2.022 \\
\hline rSMG x genotype & 2.318 & $.007^{*}$ & 10.152 & 2.516 & $.005^{*}$ & 12.377 & -1.814 & $.035^{*}$ & .163 \\
\hline \multicolumn{10}{|l|}{ Prediction accuracy } \\
\hline Autism & & $75.7 \%$ & & & $75.0 \%$ & & & $72.2 \%$ & \\
\hline Control & & $63.6 \%$ & & & $65.6 \%$ & & & $59.4 \%$ & \\
\hline Overall & & $70.0 \%$ & & & $70.6 \%$ & & & $66.2 \%$ & \\
\hline
\end{tabular}

$O R$ odds ratio, $r S M G$ right supramarginal gyrus

*Values significant at the $p<.05$ level

congruent and incongruent conditions for self and other was used as the outcome measure. Another study reported no behavioural differences in performance on the EEB task between adults with and without an autism diagnosis, nor did they find differences in resting state rSMG connectivity between groups [89]. The findings of the current study suggest that the OXTR can explain some of the within-group variability in self-other differentiation, which is not otherwise captured by comparing individuals with and without autism.

Other studies that examined OXTR genotype within typical populations usually implicate areas of the social brain other than the rSMG, such as the amygdala or the ACC [50,67-69, 90]. One possible explanation for the results lies in the specific contrast used in the current analysis. We compared participants' brain activity in response to similar images but using different prompts-sex judgments versus mental states judgments. It is possible that during the sex judgments, an automatic, implicit processing of mental states was performed. Therefore, the unexpected activation pattern in the current study could be a result of this different type of comparison. Importantly, an analysis of the full sample, from which the current sample was drawn, revealed differential activation within the inferior frontal gyrus, temporal pole, and retrosubicular area [74]. It is the addition of the genotype information (within a subsample) which revealed a different effect. Therefore, a careful interpretation of the current findings in light of the aforementioned previous research is that differential activity in the rSMG, together with genotype, is a marker of self-other distinction, crucial for the ability to correctly interpret the other's mental state (as opposed to over-relying on one's own mental state). Recent research suggests that the rSMG is connected to other brain areas involved in empathy (anterior insula and anterior cingulate cortex) and is responsible for self-other differentiation in relation to empathic processing [91]. It has been recently proposed that the observed deficit in empathy in autism could be due to a reduced ability to differentiate between self and other in the social domain [92]. This interpretation of the findings is in line with research pointing to the role of oxytocin as modulating the salience of social stimuli [57, 93, 94], and perhaps more accurately shifting one's focus from self to other.

Several limitations beg a cautious interpretation of the current findings. It is important to note that an adolescent sample was used in this study. On the one hand, this constitutes a limitation, as developmental and pubertal stages have not been directly assessed. However, we dealt with this by controlling for age and sex, as well as creating a study-specific brain template based on the age and sex composition of the participants. On the other hand, the adolescent sample is a strength of this study as few studies have focused on this age group. In addition, while brain overgrowth in the early stages of development has been repeatedly associated with autism [95], many of these brain differences tend to disappear as children grow older, and brain volume during adolescence is comparable to that of typically developing children [96].Although, one study reported on accelarated cortical thinning during adolescence, as compared to typical adolescents [99]. Later in life brain volume decreases faster in autism as compared to typical adults [97, 98].Although another study reported on accelerated cortical thinning during adolescence, as compared to typical adolescents [99]. As such, the current study highlights effects that persist into later stages of development, but findings should be interpreted with caution, and future research would benefit from investigating similar effects in other age groups, taking a developmental approach. Another limitation is that of sample size, although our sample size was modest as compared to 
other imaging genetics studies. We emphasise that, due to the exploratory nature of the current study, replication and extension studies are needed to substantiate the current findings.

\section{Conclusions}

This is one of the first studies, to our knowledge, to incorporate OXTR genotype and brain function data in order to better understand the biological underpinnings of social cognition and cognitive empathy in autism. The current study further supports the involvement of oxytocin in the aetiology of autism and simultaneously suggests a mechanism for this effect, through activation of the rSMG, an important part of the social brain, in response to a test of cognitive empathy. Future studies, utilising larger samples, are needed to substantiate this effect and can be further used to answer additional questions, for example, regarding the role of sex and circulating levels of oxytocin on these effects. Given the preliminary findings that implicate oxytocin as a therapeutic target, a greater understanding of the mechanism by which oxytocin is involved in autism from genetics to brain function, and how it contributes to variability within autism, can advance the development of precise therapeutic (both medical and non-medical) interventions.

\section{Additional file}

Additional file 1: Figure S1. Analysis of residual head movement based on DVARS, which is a time series of the root mean squares (RMS) of the derivatives of the timecourses of all within-brain voxels for each volume. The analysis was conducted using code publishes by the Brain and Mind Lab at Aalto University, Finland. (PDF $345 \mathrm{~kb}$ )

\section{Abbreviations}

ACC: Anterior cingulate cortex; ASD: Autism spectrum disorders; DMN: Default mode network; dmPFC: Dorsomedial prefrontal cortex; EEB: Emotional egocentricity bias; fMRI: Functional magnetic resonance imaging; NAcc: Nucleus accumbens; OXT: Oxytocin; OXTR: Oxytocin receptor; rIPL: Right inferior parietal lobule; rSMG: Right supramarginal gyrus; SNP: Single nucleotide polymorphism; TMS: Transcranial magnetic stimulation

\section{Acknowledgements}

Not applicable.

\section{Funding}

FU was supported by the Israel Science Foundation (grant no. 449/14), the British Friends of Haifa University, the British Friends of the Hebrew University and the Joseph Levy charitable foundation. MDS was supported by an MRC Clinician Scientist Fellowship from the UK Medical Research Council (G0701919). LRC was supported by the Gates Cambridge Scholarship Trust. RB was supported by the Pinsent Darwin Trust, Medical Research Council UK and Cambridge Trusts. AR was supported by the MRC and William Binks Autism Neuroscience Fellowship. SBC was supported by the MRC, Wellcome Trust, and the Autism Research Trust during the period of this work. The research was conducted in association with the National Institute for Health Research (NIHR) Collaboration for Leadership in Applied Health Research and Care East of England at Cambridgeshire and Peterborough NHS Foundation
Trust. The views expressed are those of the author(s) and not necessarily those of the NHS, the NIHR or the Department of Health.

\section{Availability of data and materials}

The datasets generated and/or analysed during the current study are not publicly available because brain scans are identifiable, and consent from participants did not cover data sharing, but are available from the corresponding author on reasonable request.

\section{Authors' contributions}

FU designed the current study, analysed the data, and wrote the manuscript $R A B$ and $A R$ helped with data analysis and provided critical reviews of the data analytical plan and the manuscript. RH, MS, LC, and DF were involved in data collection and provided critical comments on the paper. MS designed the study. WW, BC, EB, and JS designed the study and provided input for the writing and data analyses. SBC designed the study and provided critical input on data analyses and the writing of the manuscript. All authors read and approved the final manuscript.

\section{Ethics approval and consent to participate}

All procedures contributing to this work complied with the ethical standards of the relevant national and institutional committees on human experimentation and with the Declaration of Helsinki of 1975, as revised in 2008.

Consent for publication

Not applicable.

\section{Competing interests}

The authors declare that they have no competing interests.

\section{Publisher's Note}

Springer Nature remains neutral with regard to jurisdictional claims in published maps and institutional affiliations.

\section{Author details}

'Department of Psychology and Zlotowski Center for Neuroscience, Ben Gurion University of the Negev, 84105 Be'er Sheva, Israel. ${ }^{2}$ Autism Research Centre, Department of Psychiatry, University of Cambridge, Cambridge, UK. ${ }^{3}$ Department of Psychology, University of Haifa, Haifa, Israel. ${ }^{4}$ School of Psychology and Clinical Language Sciences, University of Reading, Reading, UK. ${ }^{5}$ Department of Child and Adolescent Psychiatry, New York University, New York, USA. ${ }^{6}$ CLASS Clinic, Cambridgeshire and Peterborough NHS Trust, Peterborough, UK.

Received: 15 July 2018 Accepted: 4 February 2019

Published online: 12 March 2019

\section{References}

1. Jones AP, FGE H, Gilbert F, Burnett S, Viding E. Feeling, caring, knowing different types of empathy deficit in boys with psychopathic tendencies and autism spectrum disorder. J Child Psychol Psychiatry. 2010;51(11): $1188-97$.

2. Lawrence EJ, Shaw P, Baker D, Baron-Cohen S, David AS. Measuring empathy: reliability and validity of the Empathy Quotient. Psychol Med. 2004;34(5):911-20.

3. Baron-Cohen S, Wheelwright S, Hill J, Raste Y, Plumb I. The "Reading the Mind in the Eyes" test revised version: a study with normal adults, and adults with Asperger syndrome or high-functioning autism. J Child Psychol Psychiatry. 2001;42(2):241-51.

4. Rueda P, Fernández-Berrocal P, Baron-Cohen S. Dissociation between cognitive and affective empathy in youth with Asperger Syndrome. Eur J Dev Psychol. 2015;12(1):85-98.

5. Baron-Cohen $\mathrm{S}$, Wheelwright $\mathrm{S}$. The empathy quotient: an investigation of adults with Asperger syndrome or high functioning autism, and normal sex differences. J Autism Dev Disord. 2004;34(2):163-75.

6. Lombardo MV, Lai M-C, Auyeung B, Holt RJ, Allison C, Smith P, et al. Unsupervised data-driven stratification of mentalizing heterogeneity in autism. bioRxiv. 2016.

7. Warrier V, Grasby KL, Uzefovsky F, Toro R, Smith P, Chakrabarti B, et al. Genome-wide meta-analysis of cognitive empathy: heritability, and 
correlates with sex, neuropsychiatric conditions and cognition. Mol Psychiatry. 2018;23:1402-409.

8. Geschwind DH, Levitt P. Autism spectrum disorders: developmental disconnection syndromes. Curr Opin Neurobiol. 2007;17(1):103-11.

9. Bill BR, Geschwind DH. Genetic advances in autism: heterogeneity and convergence on shared pathways. Curr Opin Genet Dev. 2009;19(3):271-8.

10. Gaugler T, Klei L, Sanders SJ, Bodea CA, Goldberg AP, Lee AB, et al. Most genetic risk for autism resides with common variation. Nat Genet. 2014; 46(8):881-5

11. Byrge L, Dubois J, Tyszka JM, Adolphs R, Kennedy DP. Idiosyncratic brain activation patterns are associated with poor social comprehension in autism. J Neurosci. 2015;35(14):5837-50.

12. Haar S, Berman S, Behrmann M, Dinstein I. Anatomical abnormalities in autism? Cerebral Cortex. 2014.

13. Hahamy A, Behrmann M, Malach R. The idiosyncratic brain: distortion of spontaneous connectivity patterns in autism spectrum disorder. Nat Neurosci. 2015;18(2):302-9.

14. Ameis SH, Szatmari P. Imaging-genetics in autism spectrum disorder: advances, translational impact and future directions. Frontiers Psychiatry. 2012;3.

15. Viding E, Williamson DE, Hariri AR. Developmental imaging genetics: challenges and promises for translational research. Dev Psychopathol. 2006; 18(03):877-92.

16. Feldman R, Monakhov M, Pratt M, Ebstein RP. Oxytocin pathway genes: evolutionary ancient system impacting on human affiliation, sociality, and psychopathology. Biological Psychiatry. 2016;79(3):174-84.

17. Shamay-Tsoory S, Young LJ. Understanding the oxytocin system and its relevance to psychiatry. Biol Psychiatry. 2016;79(3):150-2.

18. Kanat M, Heinrichs M, Domes G. Oxytocin and the social brain: neural mechanisms and perspectives in human research. Brain Res. 2014;1580:160-71.

19. Carter CS. Oxytocin pathways and the evolution of human behavior. Annu Rev Psychol. 2014;65(1):17-39.

20. Green MF, Horan WP, Lee J. Social cognition in schizophrenia. Nat Rev Neurosci. 2015;16(10):620-31.

21. Adolphs R. The social brain: neural basis of social knowledge. Annu Rev Psychology. 2009;60:693-716

22. Paloyelis Y, Doyle OM, Zelaya FO, Maltezos S, Williams SC, Fotopoulou A, et al. A spatiotemporal profile of in vivo cerebral blood flow changes following intranasal oxytocin in humans. Biol Psychiatry. 2016; 79(8):693-705.

23. Bethlehem RAI, Lombardo MV, Lai M-C, Auyeung B, Crockford SK, Deakin J, Baron-Cohen S. Intranasal oxytocin enhances intrinsic corticostriatal functional connectivity in women. Transl Psychiatry. 2017;7(4):e1099. https:// doi.org/10.1038/tp.2017.72.

24. Di Napoli A, Warrier V, Baron-Cohen S, Chakrabarti B. Genetic variation in the oxytocin receptor (OXTR) gene is associated with Asperger Syndrome. Mol Autism. 2014;5(1):1-7.

25. LoParo D, Waldman ID. The oxytocin receptor gene (OXTR) is associated with autism spectrum disorder: a meta-analysis. Mol Psychiatry. 2015;20(5):640-6.

26. Wu S, Jia M, Ruan Y, Liu J, Guo Y, Shuang M, et al. Positive association of the oxytocin receptor gene (OXTR) with autism in the Chinese Han population. Biol Psychiatry. 2005;58(1):74-7.

27. Jacob S, Brune CW, Carter CS, Leventhal BL, Lord C, Cook EH Jr. Association of the oxytocin receptor gene (OXTR) in Caucasian children and adolescents with autism. Neurosci Lett. 2007;417(1):6-9.

28. Lerer E, Levi S, Salomon S, Darvasi A, Yirmiya N, Ebstein RP. Association between the oxytocin receptor (OXTR) gene and autism: relationship to Vineland Adaptive Behavior Scales and cognition. Mol Psychiatry. 2007; 13(10):980-8.

29. Liu X, Kawamura Y, Shimada T, Otowa T, Koishi S, Sugiyama T, et al. Association of the oxytocin receptor (OXTR) gene polymorphisms with autism spectrum disorder (ASD) in the Japanese population. J Hum Genet. 2010;55(3):137-41.

30. Wermter A-K, Kamp-Becker I, Hesse P, Schulte-Körne G, Strauch K, Remschmidt $\mathrm{H}$. Evidence for the involvement of genetic variation in the oxytocin receptor gene (OXTR) in the etiology of autistic disorders on highfunctioning level. Am J Med Genet Part B: Neuropsychiatr Genet. 2010; 153B(2):629-39.

31. Campbell DB, Datta D, Jones ST, Batey Lee E, Sutcliffe JS, Hammock EAD, et al. Association of oxytocin receptor (OXTR) gene variants with multiple phenotype domains of autism spectrum disorder. J Neurodev Disord. 2011; $3(2): 101-12$
32. Parker KJ, Garner JP, Libove RA, Hyde SA, Hornbeak KB, Carson DS, et al. Plasma oxytocin concentrations and OXTR polymorphisms predict social impairments in children with and without autism spectrum disorder. Proc Natl Acad Sci. 2014;111(33):12258-63.

33. Tansey KE, Brookes KJ, Hill MJ, Cochrane LE, Gill M, Skuse D, et al. Oxytocin receptor (OXTR) does not play a major role in the aetiology of autism: genetic and molecular studies. Neurosci Lett. 2010;474(3):163-7.

34. Bakermans-Kranenburg MJ, van IJzendoorn MH. A sociability gene? Metaanalysis of oxytocin receptor genotype effects in humans. Psychiatr Genet. 2014;24(2):45-51.

35. Warrier V, Chee V, Smith P, Chakrabarti B, Baron-Cohen S. A comprehensive meta-analysis of common genetic variants in autism spectrum conditions. Molecular Autism. 2015;6(1):49.

36. Gregory SG, Connelly JJ, Towers AJ, Johnson J, Biscocho D, Markunas CA, et al. Genomic and epigenetic evidence for oxytocin receptor deficiency in autism. BMC Med. 2009;7.

37. Jack A, Connelly JJ, Morris JP. DNA methylation of the oxytocin receptor gene predicts neural response to ambiguous social stimuli. Front Hum Neurosci. 2012;6.

38. Andari E, Duhamel J-R, Zalla T, Herbrecht E, Leboyer M, Sirigu A. Promoting social behavior with oxytocin in high-functioning autism spectrum disorders. Proc Natl Acad Sci. 2010;107(9):4389-94.

39. Bakermans-Kranenburg MJ, van ljzendoorn MH. Sniffing around oxytocin: review and meta-analyses of trials in healthy and clinical groups with implications for pharmacotherapy. Transl Psychiatry. 2013;3:e258.

40. Aoki Y, Yahata N, Watanabe T, Takano Y, Kawakubo Y, Kuwabara H, et al. Oxytocin improves behavioural and neural deficits in inferring others' social emotions in autism. Brain. 2014.

41. Watanabe T, Kuroda M, Kuwabara H, Aoki Y, Iwashiro N, Tatsunobu N, et al. Clinical and neural effects of six-week administration of oxytocin on core symptoms of autism. Brain. 2015;138(11):3400-12.

42. Anagnostou E, Soorya L, Chaplin W, Bartz J, Halpern D, Wasserman S, et al. Intranasal oxytocin versus placebo in the treatment of adults with autism spectrum disorders: a randomized controlled trial. Mol Autism. 2012;3(1):1-9.

43. Guastella AJ, Einfeld SL, Gray KM, Rinehart NJ, Tonge BJ, Lambert TJ, et al. Intranasal oxytocin improves emotion recognition for youth with autism spectrum disorders. Biol Psychiatry. 2010;67.

44. Auyeung B, Lombardo MV, Heinrichs M, Chakrabarti B, Sule A, Deakin JB, et al. Oxytocin increases eye contact during a real-time, naturalistic social interaction in males with and without autism. Transl Psychiatry. 2015;5:e507.

45. Ooi YP, Weng S-J, Kossowsky J, Gerger H, Oxytocin SM. Autism spectrum disorders: a systematic review and meta-analysis of randomized controlled trials. Pharmacopsychiatry. 2017;50(01):5-13.

46. Guastella AJ, Gray KM, Rinehart NJ, Alvares GA, Tonge BJ, Hickie IB, et al. The effects of a course of intranasal oxytocin on social behaviors in youth diagnosed with autism spectrum disorders: a randomized controlled trial. J Child Psychol Psychiatry. 2015;56(4):444-52.

47. Rodrigues SM, Saslow LR, Garcia N, John OP, Keltner D. Oxytocin receptor genetic variation relates to empathy and stress reactivity in humans. Proc Natl Acad Sci. 2009;106(50):21437-41.

48. Weisman O, Pelphrey KA, Leckman JF, Feldman R, Lu Y, Chong A, et al. The association between 2D:4D ratio and cognitive empathy is contingent on a common polymorphism in the oxytocin receptor gene (OXTR rs53576). Psychoneuroendocrinology. 2015;58:23-32.

49. Uzefovsky F, Shalev I, Israel S, Edelman S, Raz Y, Mankuta D, Knafo-Noam A, Ebstein RP. Oxytocin receptor and vasopressin receptor 1a genes are respectively associated with emotional and cognitive empathy. Horm Behav. 2015;67:60-5

50. Laursen HR, Siebner HR, Haren T, Madsen K, Groenlund R, Hulme O, et al. Variation in the oxytocin receptor gene is associated with behavioral and neural correlates of empathic accuracy. Front Behav Neurosci. 2014;8.

51. Israel S, Lerer E, Shalev I, Uzefovsky F, Riebold M, Laiba E, et al. The oxytocin receptor (OXTR) contributes to prosocial fund allocations in the dictator game and the social value orientations task. PLOS ONE. 2009;4(5):e5535.

52. Wu N, Su Y. Oxytocin receptor gene relates to theory of mind and prosocial behavior in children. J Cogn Dev. 2015;16(2):302-13.

53. Walum H, Lichtenstein P, Neiderhiser JM, Reiss D, Ganiban JM, Spotts EL, et al. Variation in the oxytocin receptor gene is associated with pair-bonding and social behavior. Biol Psychiatry. 2012;71(5):419-26.

54. Feldman R, Zagoory-Sharon O, Weisman O, Schneiderman I, Gordon I, Maoz $\mathrm{R}$, et al. Sensitive parenting is associated with plasma oxytocin and 
polymorphisms in the OXTR and CD38 genes. Biol Psychiatry. 2012;72(3) 175-81.

55. Van ljzendoorn MH, Bakermans-Kranenburg MJ. A sniff of trust: metaanalysis of the effects of intranasal oxytocin administration on face recognition, trust to in-group, and trust to out-group. Psychoneuroendocrinology. 2012;37(3):438-43

56. Domes G, Heinrichs M, Michel A, Berger C, Herpertz SC. Oxytocin omproves "mind-reading" in humans. Biol Psychiatry. 2007;61(6):731-3.

57. Bartz JA, Zaki J, Bolger N, Ochsner KN. Social effects of oxytocin in humans: context and person matter. Trends Cogn Sci. 2011;15(7):301-9.

58. Baron-Cohen S, Wheelwright S, Skinner R, Martin J, Clubley E. The autismspectrum quotient (AQ): evidence from Asperger syndrome/highfunctioning autism, males and females, scientists and mathematicians. J Autism Dev Disord. 2001;31.

59. Bartz JA, Zaki J, Bolger N, Hollander E, Ludwig NN, Kolevzon A, et al. Oxytocin selectively improves empathic accuracy. Psychol Sci. 2010;21(10): $1426-8$

60. Bethlehem RAl, van Honk J, Auyeung B, Baron-Cohen S. Oxytocin, brain physiology, and functional connectivity: a review of intranasal oxytocin fMRI studies. Psychoneuroendocrinology. 2013;38(7):962-74.

61. Meyer-Lindenberg A, Domes G, Kirsch P, Heinrichs M. Oxytocin and vasopressin in the human brain: social neuropeptides for translational medicine. Nat Rev Neurosci. 2011;12(9):524-38.

62. Watanabe $\mathrm{T}$, Abe $\mathrm{O}$, Kuwabara $\mathrm{H}$, et al. Mitigation of sociocommunicational deficits of autism through oxytocin-induced recovery of medial prefrontal activity: a randomized trial. JAMA Psychiatry. 2014;71(2):166-75.

63. Watanabe T, Otowa T, Abe O, Kuwabara H, Aoki Y, Natsubori T, et al. Oxytocin receptor gene variations predict neural and behavioral response to oxytocin in autism. Soc Cogn Affect Neurosci. 2017;12(3):496-506.

64. Hernandez LM, Krasileva K, Green SA, Sherman LE, Ponting C, McCarron R, et al. Additive effects of oxytocin receptor gene polymorphisms on reward circuitry in youth with autism. Mol Psychiatry. 2016.

65. Inoue $H$, Yamasue $H$, Tochigi M, Abe O, Liu $X$, Kawamura $Y$, et al. Association between the oxytocin receptor gene and amygdalar volume in healthy adults. Biol Psychiatry. 2010;68(11):1066-72.

66. Tost H, Kolachana B, Verchinski BA, Bilek E, Goldman AL, Mattay VS, et al. Neurogenetic effects of OXTR rs2254298 in the extended limbic system of healthy Caucasian adults. Biol Psychiatry. 2011;70(9):e37-e9.

67. Furman DJ, Chen MC, Gotlib IH. Variant in oxytocin receptor gene is associated with amygdala volume. Psychoneuroendocrinology. 2011;36(6):891-7.

68. Wang J, Qin W, Liu B, Wang D, Zhang Y, Jiang T, et al. Variant in OXTR gene and functional connectivity of the hypothalamus in normal subjects. Neurolmage. 2013;81:199-204.

69. Tost H, Kolachana B, Hakimi S, Lemaitre H, Verchinski BA, Mattay VS, et al. A common allele in the oxytocin receptor gene (OXTR) impacts prosocial temperament and human hypothalamic-limbic structure and function. Proc Natl Acad Sci. 2010;107(31):13936-41.

70. Wang J, Qin W, Liu B, Zhou Y, Wang D, Zhang Y, et al. Neural mechanisms of oxytocin receptor gene mediating anxiety-related temperament. Brain Struct Funct. 2014;219(5):1543-54.

71. Damiano CR, Aloi J, Dunlap K, Burrus CJ, Mosner MG, Kozink RV, et al. Association between the oxytocin receptor (OXTR) gene and mesolimbic responses to rewards. Mol Autism. 2014;5(1):7.

72. Wang J, Braskie MN, Hafzalla GW, Faskowitz J, McMahon KL, de Zubicaray GI, et al. Relationship of a common OXTR gene variant to brain structure and default mode network function in healthy humans. Neurolmage. 2017;147:500-6.

73. Marusak HA, Furman DJ, Kuruvadi N, Shattuck DW, Joshi SH, Joshi AA, et al. Amygdala responses to salient social cues vary with oxytocin receptor genotype in youth. Neuropsychologia. 2015;79(Pt A):1-9.

74. Holt RJ, Chura LR, Lai M-C, Suckling J, von dem Hagen E, Calder AJ, et al. 'Reading the Mind in the Eyes': an fMRI study of adolescents with autism and their siblings. Psychol Med. 2014;44(15):3215-27.

75. Lord C, Risi S, Lambrecht L, Cook EH, Leventhal BL, DiLavore PC, et al. The autism diagnostic observation schedule - generic: a standard measure of social and communication deficits associated with the spectrum of autism. J Autism Dev Disord. 2000;30(3):205-23.

76. Le Couteur A, Lord C, Rutter M. The autism diagnostic interview-revised (ADI-R). Los Angeles, CA: Western Psychol Serv. 2003.

77. Wechsler D. Wechsler abbreviated scale of intelligence: psychological corporation; 1999
78. Baron-Cohen S, Hoekstra RA, Knickmeyer R, Wheelwright S. The autismspectrum quotient (AQ) —adolescent version. J Autism Dev Disord. 2006; 36(3):343-50.

79. Freeman B, Smith N, Curtis C, Huckett L, Mill J, Craig IW. DNA from buccal swabs recruited by mail: evaluation of storage effects on long-term stability and suitability for multiplex polymerase chain reaction genotyping. Behav Genet. 2003;33(1):67-72.

80. Machiela MJ, Chanock SJ. LDlink: a web-based application for exploring population-specific haplotype structure and linking correlated alleles of possible functional variants. Bioinformatics (Oxford, England). 2015;31(21): 3555-7.

81. Ashburner J, Friston KJ. Unified segmentation. Neurolmage. 2005;26(3):839-51.

82. Wilke M, Holland SK, Altaye M, Gaser C. Template-O-Matic: a toolbox for creating customized pediatric templates. Neurolmage. 2008;41(3):903-13.

83. Eickhoff SB, Stephan KE, Mohlberg H, Grefkes C, Fink GR, Amunts K, et al. A new SPM toolbox for combining probabilistic cytoarchitectonic maps and functional imaging data. Neurolmage. 2005;25(4):1325-35.

84. Brett M, Anton J-L, Valabregue R, Poline J-B. Region of interest analysis using the MarsBar toolbox for SPM 99. Neurolmage. 2002;16(2):S497.

85. Jenkinson M, Beckmann CF, Behrens TEJ, Woolrich MW, Smith SM. FSL. Neurolmage. 2012;62(2):782-90.

86. Rorden C, Karnath H-O, Bonilha L. Improving lesion-symptom mapping. J Cogn Neurosci. 2007;19(7):1081-8.

87. Tzourio-Mazoyer N, Landeau B, Papathanassiou D, Crivello F, Etard O, Delcroix N, et al. Automated anatomical labeling of activations in SPM using a macroscopic anatomical parcellation of the MNI MRI single-subject brain. Neurolmage. 2002;15(1):273-89.

88. Silani G, Lamm C, Ruff CC, Singer T. Right supramarginal gyrus is crucial to overcome emotional egocentricity bias in social judgments. J Neurosci. 2013;33(39):15466-76.

89. Hoffmann F, Koehne S, Steinbeis N, Dziobek I, Singer T. Preserved self-other distinction during empathy in autism is linked to network integrity of right supramarginal gyrus. J Autism Dev Disord. 2016;46(2):637-48.

90. Dannlowski U. Disadvantage of social sensitivity: interaction of oxytocin receptor genotype and child maltreatment on brain structure. Eur Psychiatry. 41:S20.

91. Steinbeis N. The role of self-other distinction in understanding others' mental and emotional states: neurocognitive mechanisms in children and adults. Philosophical Transactions of the Royal Society B: Biological Sciences. 2016;371(1686)

92. Lamm C, Bukowski H, Silani G. From shared to distinct self-other representations in empathy: evidence from neurotypical function and sociocognitive disorders. Philos Trans R Soc B. 2016;371(1686).

93. Shamay-Tsoory SG, Abu-Akel A. The social salience hypothesis of oxytocin. Biol Psychiatry. 2016;79(3):194-202.

94. Bethlehem RA, Baron-Cohen S, van Honk J, Auyeung B, Bos PA. The oxytocin paradox. Oxytocin's routes in social behavior: into the 21st century "Precision Medicine" approach for oxytocin. 2015:116.

95. Aylward EH, Minshew NJ, Field K, Sparks BF, Singh N. Effects of age on brain volume and head circumference in autism. Neurology. 2002;59(2):175-83.

96. Lange N, Travers BG, Bigler ED, Prigge MBD, Froehlich AL, Nielsen JA, et al. Longitudinal volumetric brain changes in autism spectrum disorder ages 635 years. Autism Res. 2015;8(1):82-93.

97. Courchesne E, Campbell K, Solso S. Brain growth across the life span in autism: age-specific changes in anatomical pathology. Brain Res. 2011;1380: $138-45$.

98. Chow ML, Pramparo T, Winn ME, Barnes CC, Li H-R, Weiss L, et al. Agedependent brain gene expression and copy number anomalies in autism suggest distinct pathological processes at young versus mature ages. PLoS Genet. 2012;8(3):e1002592.

99. Zielinski BA, Prigge MBD, Nielsen JA, Froehlich AL, Abildskov TJ, Anderson $J \mathrm{~S}$, et al. Longitudinal changes in cortical thickness in autism and typical development. Brain. 2014;137(6):1799-812. 